\section{Design Patterns for Managing Up}

FOUR

CHALLENGING

WORK SITUATIONS

AND HOW TO

HANDLE THEM

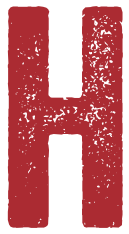

ave you ever been in a situation where you are presenting to your manager or your manager's manager and you completely flub the opportunity by saying all the wrong things? Me too. It is from such encounters that I started to put together design patterns for handling these difficult situations. I like to think in systems and patterns, so applying this way of thinking to communication just makes sense. I have also found that these rules of thumb are useful to others, so I would like to share them here.

When you can spot the patterns, you can use some of the ideas presented here as guidelines to navigate these tricky, high-stress scenarios. This way you can feel confident and capable as a leader because you will know what to do: how to solve the problem and what steps to follow next.

Here are some of the most common challenging situations you may run into at work and how you can handle them.

1. Someone asks you something you don't know You are in a meeting (where you know you

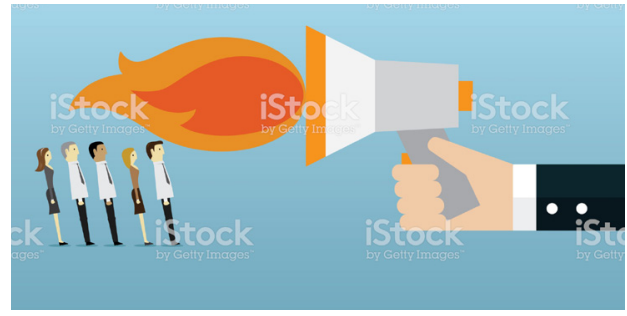


are expected to know all the answers] when someone asks a question of you, and you just aren't certain of the answer.

Sure, the obvious answer is to say, "I don't know." But what if the person asking you that question is a customer? What if that person is your VP? What if you are interviewing for a new role? Suddenly, the stakes are raised and you just don't want to say, "I don't know." You don't want to look uninformed or unprofessional. All of a sudden there is social pressure to be the person with the right answer.

In the moment, the desire to say anything but "I don't know" is so overwhelming that you may end up making up something on the spot, trying to be as vague as possible so you can't be wrong. But-as you know if someone has done this to you-it's usually obvious to the other people in the room that you don't know the answer, and now that interaction will negatively color their view of you.

They still end up knowing that you don't know, but now you've also wasted their time. Or even worse, you give them an answer you think is correct, but you turn out to be wrong. Then you're in a situation where you actually are uninformed, and you are left crossing your fingers hoping no one will ever find out.

If you take the long view, you will realize that it is always much better to admit that you don't know something, but then take action to fix it.

In this case the pattern is:

1. Admit you aren't certain.

2. Own the follow-up to determine the answer.

3. Give a timeline for when you will follow up.

4. Deliver a correct, concise, and thoughtful response.

When you say, "I don't know, but I can investigate and get 
back to you after lunch" or "I don't know, but does and I will ask her and get back to you by the end of the day," suddenly you are a person solving a problem.

Any time you don't know, be clear that you don't know, but follow up with a plan for how you'll get the information and with a deadline for conveying that information. That is all the person asking the question really wants anyway: for you to supply the answer.

Smart people don't know everything; they just know where to look to find out what they need to know.

\section{There is a problem that is your fault or responsibility} Have you ever been in a situation where something went wrong [such as a system outage] and you wanted to figure out the causelsolution to the problem before broadcasting it more widely? I know this is how I feel-especially if keeping that system up and running is my [or my team's] responsibility.

When problems occur, there is a natural instinct to hide or deny that the problem is a problem, or that it is even happening at all. We want to minimize the problems that are our responsibility because, after all, a big part of our job is to make sure problems don't happen. When you are proactive about sharing and fixing a problem, however, it is actually an opportunity to show you are an asset to the bosses.

In general, it is always better to control the message and have your management learn of the problem from you (instead of a customer or a boss). Great leadership is keeping everyone on the same page, and it is your job to communicate proactively so that there are no surprises.

If your system experiences an outage or any other 
customer-impacting issue, you should be the first person to share the issue with your manager, customers, team, or whoever is affected by the problem. This makes you the proactive one who discovered the problem and are already working to address it before anyone else even knows about it.

For this pattern the steps are:

1. Let the key people know that you know about the problem and are working on a solution. Establish yourself as the owner and let them know you will see this through to the finish.

2. Share steps if you know them, but if you don't know the answer, let the key people know when you will provide the next update [e.g., "We aren't sure what caused the problem, or the impact, but will provide another update in an hour"].

3. Give a timeline. This is the most important thing you can do. When will the problem be fixed? If you don't know when or how it will be fixed yet, when will you provide an update? What possible solutions are you going to try and when will you know the results?

Give specific answers to specific questions. It is never okay just to say, "We're working on it."

Even if all you can say is that you're aware and will update with more information at a specific time, then you are at least able to fulfill a promise to your bossl team/customer by following through and giving them an update at the specified later time. This is far better than making them wait in radio silence while you try to figure out what's going on. They will spend that time feeling negative about you or your team, which only amplifies the 
impact of the problem.

Tip: Look for ways you can help your customers avoid having a bad experience with your product, whether with a notification letting them know about the problems or pointers to documentation to help them work around it.

\section{There is a decision that you don't agree with}

When you care a lot about your work, it can be really hard to get behind a decision you don't agree with. You might feel like it is worth speaking up-but this can be challenging when that decision is made by someone who is one, two, or more levels above you.

Sure, many technology execs claim they want everyone who disagrees to raise questions, but is that something you really want to gamble your career on? When it comes to navigating these situations, there is generally a right way and a wrong way to disagree.

When you first hear about a decision that you think is a bad call-such as a re-org or a new feature that you believe is a waste of time-it can be a really fraught moment. You might feel frustrated or angry, which can lead you to give an overly emotional response that is both unproductive and ineffective.

Remember there is someone in the chain who thinks this is a good idea; that is why it is being implemented. So, it is worth your time to try to understand the "why" behind this idea-it just might change your mind, and even if it doesn't, it will give you the context you need to make an argument that could actually convince the decision maker that you are right.

Next time there is a decision that you don't agree with, 


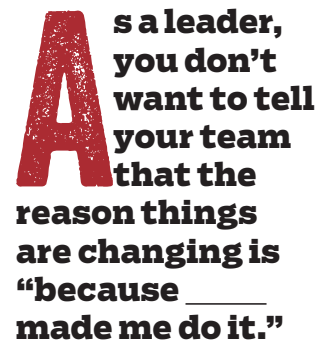

s a leader, you don't want to tell your team that the reason things are changing is "because made me do it." instead of jumping to "no," try asking about the goal. What is this person trying to achieve? If you still don't agree with the explanation, you can try researching the problem and providing an alternative plan. (You will always be taken more seriously if you can provide another solution instead of just saying the current plan is a bad idea.)

Sometimes you won't change anyone's mind. If this is the case, then it's time to shift your perspective and implement the change as it has been outlined to you. Even so, there is still a benefit to understanding the reasoning behind a change you don't agree with.

As a leader, you don't want to tell your team that the reason things are changing is "because _ made me do it." That makes it seem like you have no power, as though you do things just because you are told to. It certainly won't inspire confidence in your team or make them any more likely to embrace the decision.

Instead, you want to explain that you are implementing a change because of $X Y Z$ reason. If questioned, you can mention that you shared concerns about the plan with your leaders, but then reiterate the reasoning behind the current plan with your team. Ultimately, it is your job to commit to the organization's strategy and help your team succeed within that strategy.

There is never a 100-percent right answer at work. There are just different approaches and tradeoffs with each approach. It's not your job to agree with your leadership 100 percent of the time, but it is your job to make the company as successful as possible.

So, when a decision is made that doesn't make sense to you, here are the steps: 
1. Take the emotion out of it-wait a day or two if you need time to clear your head.

2. Don't disagree; ask about the context and reasons for the change.

3. Start with your manager or the main decision maker if you have a prior relationship, and then escalate up the chain of command together (rather than just emailing your thoughts to the CEO].

4. Research and present alternative options that will achieve the same goals.

5. If you don't succeed in swaying the decision maker, then support the plan of action. Be sure to share the context and reasoning with your team, and then do everything you can to make the situation better (which can be helping the cause succeed, mitigating fall-out, etc.].

\section{Your manager gives you negative feedback}

I have a lovelhate relationship with feedback. I love it because it is necessary to improve, but I hate it because no matter how much I try, I can't help but take it personally.

No matter how amazing you are at your job, you will sometimes get feedback about things you could be doing better. It can be difficult to hear, especially if you are someone who works really hard all the time. When it comes to negative feedback, it is important to reframe the conversation. Feedback isn't a bad thing. It is a gift, and you should always adopt a growth mindset and see it as a chance to improve.

I once had a manager give me some feedback on a meeting I had been part of. The meeting had gone off the rails, and I had done my best to get people back on track 
and focused. My manager hadn't been there, but he had been told by other people in the meeting that my tactics had rubbed some people the wrong way.

In the moment, I was frustrated. I didn't agree with the feedback at all, so I wanted to get to the bottom of it. This was a big mistake. Suddenly, my boss was on the defensive. I was asking him really direct questions: "What does that mean?" and "What could I have done differently?" I was forcing him to explain a situation he didn't really know about.

It harmed my relationship with that manager, and I had to do a lot of work to repair it.

I talked to my mentor about the situation, and my mentor reminded me that every time you get feedback it is an opportunity to grow. It is valuable, because it is a chance to learn more about how you can be better.

Keep in mind that as hard as it is to receive negative feedback, it isn't always easy for your manager to give that feedback either. No one really enjoys conveying bad news. So, handling it the right way is also an opportunity to create a positive encounter with your manager. When you get feedback that hurts or that you don't agree with, try to remain calm in the moment. Focus on slowing down your breathing, be aware of your heart rate, and try to keep your face relaxed.

Then say, "I hear you. I will be more mindful of that in the future."

That's it, and the only pattern for this one.

If your manager has more to say, he or she will say it. If you aren't clear on exactly what the person means or if you are genuinely interested in hearing suggestions for 


\section{Related articles}

$\Rightarrow$ Views from the Top

Try to see things from a manager's

perspective.

Kate Matsudaira

https://queue.acm.org/detail.cfm?id=3156692

$\Rightarrow$ People and Process

Minimizing the pain of business

process change

James Champy

https://queue.acm.org/detail.cfm?id=1122687

$\Rightarrow$ Broken Builds

Frequent broken builds could be

symptomatic of deeper problems

within a development project.

Kode Vicious

https://queue.acm.org/detail.cfm?id=1740550 what you could do next time, ask. But don't snap at this person or start giving them the third degree about the feedback. If you think you might react emotionally or angrily, then simply say the phrase above, thank your boss for the feedback, and then leave.

You can always send an email later, after you have had a chance to collect your thoughts, then get further clarification at that time. Let your boss know you have been thinking about it and took the feedback to heart. Ask in an open and authentic way for advice.

Look for patterns and be the version of yourself that you want to be Challenges come up all the time at work. Spend time now thinking about how you want to be seen at work, and then think about how that version of you would respond to the challenges that you could encounter. When you have a plan in place, you are much more likely to succeed.

I hope your find these tips useful, and if you have additional ones to add to the mix, please leave a comment.

Kate Matsudaira is an experienced technology leader. She worked in big companies such as Microsoft and Amazon and 


\title{
software
}

three successful startups (Decide acquired by eBay, Moz, and Delve Networks acquired by Limelight] before starting her own company, Popforms (https:I/popforms.com/l, which was acquired by Safari Books. Having spent her early career as a software engineer, she is deeply technical and has done leading work on distributed systems, cloud computing, and mobile. She has experience managing entire product teams and research scientists and has built her own profitable business. She is a published author, keynote speaker, and has been honored with awards such as Seattle's Top 40 under 40. She sits on the board of acmqueue and maintains a personal blog at katemats.com.

Copyright $(2018$ held by ownerlauthor. Publication rights licensed to ACM.

\section{SHAPE THE FUTURE OF COMPUTING!}

\author{
Join ACM today at acm.org/join
}

\section{BE CREATIVE. STAY CONNECTED. KEEP INVENTING.}

Association for

Computing Machinery

Advancing Computing as a Science \& Profession 